\title{
Dianas moleculares y desarrollo de nuevos fármacos antitumorales: una lucha dinámica frente a lo todavía desconocido
}

La última semana de septiembre tuvo lugar en Ginebra uno de los simposios que se están convirtiendo en clásicos e imprescindibles en el ámbito de la investigación de nuevos tratamientos contra el cáncer. Organizado por la EORTC, el NCI de los EE.UU. de norteamérica y la AACR, contó con la asistencia de más de 2.200 investigadores, con un total de 661 presentaciones en forma de charlas o paneles. Fue una excelente presentación de los más recientes avances en la identificación de nuevas dianas terapéuticas potenciales, el diseño de nuevas estrategias antitumorales y la realidad actualizada de los ensayos clínicos en fase I con las nuevas terapias. La temática del simposio abarcaba en principio un amplio espectro de temas con expectativas de atraer el interés de los participantes. El programa oficial dedicó una especial atención a los procedimientos para desarrollar los nuevos fármacos, especialmente los estudios preclínicos, incluyendo los sistemas de cultivos celulares y modelos animales, el empleo de la proteómica y la genómica y los instrumentos de regulación (FDA, EMEA). Varias sesiones remarcaron la actualidad de los inhibidores del proteosoma, los agentes modificadores de cromatina, inhibidores de la angiogénesis y vasculogénesis, agentes moduladores de la apoptosis y la supervivencia celular, reguladores de la hipoxia, y la consideración de las células de estroma como dianas terapéuticas. Obviamente, el interés real para los asistentes y la actualidad de cada uno de los aspectos tratados se pudo medir por el análisis de la presentación de comunicaciones.

Siguiendo este sencillo razonamiento, una de las estrellas del simposio fue sin duda la sección dedicada a la búsqueda de moduladores de transmisión de señales, con 101 paneles presentados. No es de extrañar, puesto que los fármacos aprobados para diferentes indicaciones tumorales de los últimos años como herceptin, gleevec o iressa, están enmarcados dentro de este ámbito de nuevos inhibidores específicos de rutas de señalización. Otros focos de máxima atención fueron el de la búsqueda de nuevas dianas terapéuticas (67 paneles) y los inhibidores de angiogénesis y metástasis (64 paneles), un área que surge después de una cierta desilusión con los primeros ensayos clínicos. También fue de destacar la continua pérdida de interés de aspectos considerados muy relevantes y generadores de grandes expectativas en los últimos años, como la terapia génica (20 paneles), los dedicados a ciclo celular (20 paneles), vacunas antitumorales (13 paneles), agentes hormonales (5 paneles) y los fármacos de origen marino (4 paneles). Es de destacar aspectos que han surgido con fuerza y mucho interés, como han sido los mencionados de los nuevos inhibidores de la angiogénesis, los relativos a los inhibidores de las acetilasas de histonas y los inhibidores del proteosoma, todos ellos también propuestos desde el comité organizador. Estos dos últimos, enzimas modificadoras de cromatina e inhibidores del proteosoma, arrancan con mucha fuerza y con una sólida investigación preclínica que les augura un futuro prometedor.

Tras las primeras impresiones in situ, y días después de la terminación de un simposio de estas características, se produce una obligada reflexión, intentado responder a las preguntas que uno se hace repetidamente desde hace unos años. ¿Hemos avanzado algo en la lucha contra el cáncer desde el descubrimienrto de los primeros oncogenes humanos? ¿Hemos sido capaces de trasladar a la clínica -a los pacientes- esperanzas fundadas de curación de esta enfermedad? ¿O hemos sido capaces simplemente de generar conocimiento no aplicable al tratamiento? La respuesta no es difícil de responder, y obliga a hacer una fuerte autocrítica de cuál es nuestra contribución real.

Dejando de lado el estusiasmo de investigador que uno siempre debe llevar puesto -de otra forma, las condiciones de trabajo son de por sí suficientemente desalentadoras como para conducir al desánimo- el enfrentarse a la realidad de los nuevos tratamientos antitumorales que están teniendo realmente éxito en la clínica no es muy alentador. Los avances son extremadamente lentos y la creación de tantas expectativas seguidas de sonados fracasos se pueden volver definitivamente en contra de los propios investigadores. Los oncólogos clínicos - y a la postre los pacientes, los medios de comunicación y la opinión públicahan sido abandonados al desánimo después de unos grandes descubrimientos en las fases preclínicas, con curaciones milagrosas de ratones que nunca se trasladan a los pacientes reales. En definitiva, el cáncer 
sigue siendo una enfermedad a la que no hemos podido vencer con aproximaciones novedosas y eficaces, salvo limitadas excepciones, y el ingente conocimiento académico generado que explican muchos aspectos de la biología molecular y celular del cáncer ha dado escasos réditos en la práctica médica. En consecuencia, sigue siendo el manejo de los fármacos convencionales y fundamentalmente citotóxicos, los que aportan algo de esperanza a los afectados. La investigación sobre nuevos fármacos, nuevas estrategias y nuevas dianas potenciales sigue estando anclada en el mundo de los futuribles.

En una serie de congresos como el que nos atañe, es muy ilustrativo ver cómo se mueven las masas de científicos de un tema a otro, con la avidez y angustia de quien no sabe muy bien a quién se enfrenta. El enemigo -el cáncer- no parece estar dispuesto a rendirse fácilmente ni a dar facilidades. Pero por dejar unas pinceladas de optimismo, sí que parece que el sentimiento general es que nos vamos acercando, y que batallas ganadas como herceptin, gleevec o iressa, con las limitaciones que todos conocemos, son un gran estímulo para continuar la travesía. Por otro lado, ha sido especialmente importante el mensaje de que es imprescindible saber a priori qué pacientes son susceptibles de beneficiarse de un nuevo tratamiento y cuáles no -el caso de iressa se ha convertido en un clásico- y de qué mecanismos disponemos para saber con certeza que los fármacos están actuando de la forma esperada en el tejido tumoral- en otras palabras, debemos poder hacer un seguimiento de la eficacia de los tratamientos. Una mejora en la selección de pacientes y en el seguimiento del tratamiento puede cambiar radicalmente nuestra forma de percibir el desarrollo de la batalla contra el cáncer.

Por ultimo, fue muy ilustrativo el "enfrentamiento dialéctico" propuesto por los organizadores en una sesión especial, entre los investigadores (representados por E. Rowinsky) y la industria farmacéutica (representada por G. Blackledge) en el que quedó de manifiesto que los intereses de unos y otros son en muchos aspectos contrapuestos. Mientras que, según Rowinsky, el investigador desea llevar los nuevos fármacos en estudio hasta el final de sus investigaciones, independientemente del resultado final, la industria -según Blackledge- está interesada en la rentabilización de los compuestos imponiendo un criterio de selectividad riguroso basado en la eficacia comparativa y los posibles beneficios. Tanto uno -el investigadorcomo otro -el responsable de la empresa farmacéutica- criticaron los problemas que genera la excesiva competencia por tener que descubrir fármacos novedosos y eficaces. No faltó tampoco la crítica teñida de queja de un representante de una empresa de biotecnología, que increpó a los ponentes y organizadores con una cuestión espinosa: ¿por qué no se consideró a las empresas de este sector en este debate? Las pequeñas empresas biotecnológicas son muy frecuentemente las fuentes de las que se alimentan la gran industria y los estudios clínicos. El debate quedó abierto y expuesto a posteriores comentarios.

Este editorial pretende animar a crear un foro de debate entre los lectores sobre los avances reales en el desarrollo de nuevas estrategias antitumorales, las razones de los recientes fracasos, el entendimiento entre investigadores preclínicos y clínicos, las condiciones actuales de trabajo de ambos colectivos y la aproximación conjunta que desde éstos se debe hacer a las empresas de biotecnología y a la gran industria farmacéutica. Hay buenos ejemplos que sirven de modelo a seguir.

Juan Carlos Lacal Executive Editor 